\title{
PENGARUH PERLAKUAN BIJI DAN MEDIA TANAM TERHADAP PERKECAMBAHAN BIJI MAHKOTA DEWA (Phaleria macrocarpa)
}

\author{
Muh. Aniar Hari Swasono \\ Staf Pengajar Fakultas Pertanian Universitas Yudharta Pasuruan
}

\begin{abstract}
Abstraksi : Penelitian ini dilakukan untuk mengetahui kecepatan tumbuh tunas pada saat perkecambahan serta mengetahui pertumbuhan awal tanaman mahkota dewa dengan berbagai perlakuan biji pada media tanam yang berbeda. Penelitian ini menggunakan Rancangan Acak Kelompok (RAK) Faktorial dengan dua faktor yaitu :faktor pertama yaitu macam perlakuan biji (B): Faktor kedua yaitu macam media perkecambahan (M). Masing-masing perlakuan diulang sebanyak 3 kali, sehingga didapat kombinasi perlakuan sebanyak 36 kombinasi perlakuan Data yang diperoleh dianalisis ragam dengan uji $\mathrm{F}$ kemudian dilanjutkan dengan uji beda nyata terkecil (BNT) pada taraf 5\%. Hasil penelitian menunjukkan bahwa perlakuan biji mahkota dewa yang berbeda memberikan pengaruh yang nyata terhadap tinggi tanaman, pada jumlah daun dan munculnya tunas berpengaruh sangat nyata, tetapi tidak berpengaruh nyata terhadap besarnya diameter batang.dan berat kering tanaman. Perlakuan media pada tanaman mahkota dewa yang berbeda memberikan pengaruh yang sangat nyata pada tinggi tanaman dan saat munculnya tunas, sedangkan pada jumlah daun, diameter batang dan berat kering berpengaruh nyata.Perlakuan terbaik dalam penelitian ini adalah B1M3 yaitu biji yang tanpa cangkang dan kulit dan media tanah ditambah pupuk kandang dengan tinggi tanaman $9,55 \mathrm{~cm}$; jumlah daun 12,76 buah ; waktu muncul bunga 12 hari setelah tanam ( 2 minggu) ; diametr batang 3,54 cm. ; berat kering tanaman 5,7 gram.
\end{abstract}

Pengobatan dengan menggunakan mahkota dewa saat ini makin diminati, sayangnya suplai buah mahkota dewa masih sangat terbatas. Dari waktu ke waktu kebutuhan akan mahkota dewa menunjukkan peningkatan, hal ini tercermin dari harganya yang cukup tinggi walaupun cukup bervariasi di lapangan. Harga buah mahkota dewa segar dapat mencapai Rp. 5.000,- sampai Rp. 20.000,- per kilogramnya. Kenyataan ini merupakan peluang usaha untuk membudidayakan mahkota dewa secara intensif ( Winarto,2004).

Membudidayakan mahkota dewa tidaklah sulit, karena tanaman ini dapat hidup optimal pada daerah tropis dengan produksi buah yang tidak mengenal musim. Akan tetapi pada proses perkecambahan memerlukan waktu agak lama karena morfologi biji yang terbungkus cangkang biji. Biji di persemaian biasanya akan tumbuh tunas kurang lebih 2-4 minggu setelah penyemaian. 


\section{METODE}

Metode penelitian menggunakan Rancangan Acak Kelompok (RAK) Faktorial dengan dua faktor yaitu :

Faktor pertama yaitu macam perlakuan biji $(\mathbf{B})$ : B1 $=$ Biji - cangkang - kulit ari $\mathbf{B 2}=$ Biji - cangkang $\mathbf{B 3}=$ Biji + cangkang + perendaman dengan air panas $\left(80^{\circ} \mathrm{C}\right)$ selama 1 Jam B4 = Biji + cangkang. Faktor kedua yaitu macam media perkecambahan $(\mathbf{M}): \mathbf{M 1}=$ Media Pasir M2 = Media Pasir + Pupuk Kandang M3 = Media Tanah + Pupuk Kandang Masing-masing perlakuan diulang sebanyak 3 kali, sehingga didapat kombinasi perlakuan sebanyak 36 kombinasi perlakuan. Pengamatan perkecambahan dilakukan mulai hari pertama hingga muncul tunas. Sedangkan pengamatan pertumbuhan meliputi tinggi tanaman, jumlah daun dan berat kering tanaman. Data yang diperoleh dianalisis ragam dengan uji F kemudian dilanjutkan dengan uji beda nyata terkecil (BNT) pada taraf 5\%.

\section{HASIL DAN PEMBAHASAN}

\section{Tinggi Tanaman}

Rata-rata tinggi tanaman pada setiap perlakuan disajikan pada gambar 1. Dimana rata-rata tinggi tanaman berkisar antara 6,90 (B3M1) sampai 9,55 cm (B1M3). Dengan ini dapat dilihat bahwa tinggi tanaman tertinggi pada B1M3 (Biji dengan media tanah dan pupuk kandang) yaitu 9,55 cm dan yang terendah yaitu B3M1 6,90 cm

Dari hasil analisis ragam terhadap tinggi tanaman menunjukkan interaksi nyata antara perlakuan media dan biji melalui uji Duncans $(\mathrm{p}=0,05)$ lampiran 1, demikian juga pada perlakuan biji menunjukkan perbedaan nyata. Sedangkan pada perlakuan media menunjukkan pengaruh yang sangat nyata.

Tabel 1. Rata-rata tinggi tanaman karena pengaruh perlakuan biji

\begin{tabular}{|c|c|c|} 
Perlakuan & Rerata & Notasi \\
\hline \hline B2 & 7,72 & $\mathrm{a}$ \\
\hline B3 & 7,79 & $\mathrm{a}$ \\
\hline B4 & 7,99 & $\mathrm{ab}$ \\
\hline B1 & 8,67 & $\mathrm{~b}$ \\
\hline \hline BNT 5 \% & $\mathbf{0 , 6 9 5}$ & \multicolumn{1}{|c|}{} \\
\hline \hline
\end{tabular}

Keterangan : angka yang didampingi huruf yang sama menyatakan tidak berbeda pada $(p=0,05)$ 
Pada tabel 1. menunjukkan bahwa pada perlakuan biji memberikan pengaruh nyata dengan uji Duncans $(\mathrm{p}=0,05)$. Dimana pada perlakuan B1 menunjukkan tinggi tanaman tertinggi tetapi tidak berbeda nyata pada B4, namun dengan B2 dan B3 menunjukkan perbedaan yang nyata.

Untuk perlakuan Biji,B1 mencapai hasil yang terbaik hal ini terjadi karena pada perlakuan ini biji tidak terhalang oleh kulit dan cangkang. Sehingga embrio akan tumbuh dan melakukan metabolisme dengan segera. Berbeda dengan perlakuan lainnya, karena adanya kulit dan cangkang yang kuat maka permeabilitas benih terhadap air rendah. Dengan tidak adanya penghalang, embrio segera tumbuh dengan melakukan metabolisme sesuai tahapannya.

Tabel 2. Rata-rata tinggi tanaman karena pengaruh media

\begin{tabular}{|c|c|c|}
\hline \hline Perlakuan & Rerata & Notasi \\
\hline \hline M2 & 7,48 & a \\
\hline M1 & 7,79 & a \\
\hline M3 & 8,86 & b \\
\hline \hline BNT 5 \% & $\mathbf{0 , 6 0 1}$ & \multicolumn{1}{|c|}{} \\
\cline { 1 - 2 }
\end{tabular}

Keterangan : angka yang didampingi huruf yang sama menyatakan tidak berbeda pada $(p=0,05)$

Pada perlakuan media tabel 2, pada M3 (tanah + pupuk kandang) menunjukkan tinggi tanaman tertinggi dan berbeda nyata pada kedua perlakuan lainnya (M1 dan M2). Ditinjau dari pengaruh media, yang terbaik adalah media tanah yang ditambah pupuk kandang (M3). Sifat fisik tanah memiliki jumlah pori-pori yang lebih daripada pasir mengakibatkan tanah memiliki daya pegang air tinggi. Sedangkan pemberian pupuk kandang dapat menambah unsur hara yang terkandung dalam tanah, memperbaiki sifat fisik dan biologis tanah serta dapat mencegah kehilangan air dalam tanah dan laju infiltrasi air.

Menurut Dawam, 1993 (dalam Nasution,1998) menyatakan bahwa pemberian pupuk kandang berpengaruh terhadap indek agregasi dan kandungan air tersedia, selain itu peranan bahan organik terhadap sifat fisik tanah adalah meningkatkan kemampuan agregat tanah, memperbaiki struktur tanah dan meningkatkan daya tahan air tanah. 
Oleh karena itu dengan media yang cukup hara dan air maka pertumbuhan embrio segera terpenuhi. Dengan begitu metabolisme dari sel-sel embrio ini akan berlangsung dan memacu pertumbuhan kecambah. Hal ini dikuatkan dengan peryataan Hari Suseno (1974), dimana metabolisme sel-sel embrio mulai setelah menyerap air, yang meliputi reaksi-reaksi perombakan yang biasa disebut katabolisme dan sintesa komponen sel-sel untuk pertumbuhan yang disebut anabolisme. Proses metabolisme ini akan berlangsung terus dan merupakan pendukung pertumbuhan kecambah hingga tanaman dewasa.

\section{Jumlah Daun}

Rata-rata jumlah daun pada setiap perlakuan bisa dilihat pada gambar 2. Dimana rata-rata jumlah daun berkisar antara 8,67 (B4M1) sampai 12,76 (B1M3). Dengan ini dapat dilihat bahwa jumlah daun terbanyak terjadi pada B1M3 12,76 sedangkan yang paling sedikit B4M1 8,67.

Dari hasil analisis ragam terhadap jumlah daun terjadi interaksi yang nyata (lampiran 2) antara perlakuan biji dan media, begitu juga pada perlakuan media. Sedangkan pada perlakuan biji menunjukkan pengaruh yang sangat nyata.

Tabel 3. Rata-rata jumlah daun karena pengaruh perlakuan biji

\begin{tabular}{|c|c|c|}
\hline \hline Perlakuan & Rerata & Notasi \\
\hline \hline B4 & 9,11 & a \\
\hline B3 & 9,18 & a \\
\hline B2 & 9,50 & a \\
\hline B1 & 11,00 & b \\
\hline \hline BNT 5\% & $\mathbf{1 , 0 0 6}$ & \\
\hline \hline
\end{tabular}

Tabel 4. Rata-rata jumlah daun karena perlakuan media

\begin{tabular}{|c|c|c|}
\hline \hline Perlakuan & Rerata & Notasi \\
\hline \hline M2 & 9,26 & $\mathrm{a}$ \\
\hline M1 & 9,45 & $\mathrm{a}$ \\
\hline M3 & 10,37 & $\mathrm{~b}$ \\
\hline \hline BNT 5\% & $\mathbf{0 , 8 7 2}$ & \multicolumn{1}{|c}{} \\
\hline \hline
\end{tabular}

Pada tabel 3 memperlihatkan bahwa pada perlakuan biji B1 (biji-cangkang-kulit) jumlah daun terbanyak, menunjukkan adanya perbedaan yang nyata terhadap B2,B3,B4. Sedangkan B4,B3,B2 tidak ada perbedaan yang signifikan. Pada perlakuan media 
menunjukkan M3 berbeda nyata dengan M1 dan M3, sedangkan M1 dan M2 tidak menunjukkan perbedaan yang signifikan. Pada M3 diperoleh jumlah daun terbanyak.

Pada perlakuan biji, biji cepat berkecambah sehingga pertumbuhannya lebih cepat. Hal ini disebabkan karena biji tidak terhalang oleh cangkang dan kulit sehingga permeabilitas terhadap air lebih cepat sehingga proses pembelahan, pembesaran dan pembagian sel pada titik-titik tumbuh khususnya pembentukan daun lebih cepat.

Pada perlakuan media, M3 diperoleh jumlah daun terbanyak. Hal ini disebabkan penambahan pupuk kandang pada media. Pupuk kandang mempengaruhi parameter pertumbuhan jumlah daun. Pupuk kandang merupakan pupuk organik selain tambahan unsur hara dalam tanah juga dapat memperbaiki sifat fisik dan biologis tanah. Pemberian pupuk kandang yang telah terdekomposisi dalam tanah menjadi bentuk senyawa yang dapat diserap oleh tanaman yang kemudian dapat dimanfaatkan oleh tanaman untuk pertumbuhannya khususnya jumlah daun.

\section{Saat Munculnya Tunas}

Rata-rata waktu muncul tunas pada setiap perlakuan disajikan pada gambar 1. Dimana rata-rata tunas berkisar antara 27,67 hari (B1M1) dan 12 hari pada B1M3. Gambar tersebut menunjukkan pada B1M3 dan B1M2 adalah perlakuan tercepat untuk munculnya tunas,pada hari ke 12 setelah tanam sudah muncul bunga.

Pengamatan pada tunas dilakukan satu kali dimana pada saat munculnya tunas pada biji. Peristiwa dimana sistem pertunasan muncul pertama kali diatas tanah disebut dengan emergence of seedling (Heddy Swasono, 1994) yang selanjutnya akan diikuti oleh pertumbuhan bibit menjadi tanaman dewasa.

Dari hasil analisis ragam terhadap munculnya tunas menunjukkan interaksi sangat nyata antara perlakuan media dan biji dengan uji Duncans $(\mathrm{p}=0,05)$ lampiran.

Tabel 5. Rata-rata saat munculnya tunas karena pengaruh perlakuan biji

\begin{tabular}{|c|c|c|}
\hline \hline Perlakuan & Rerata & Notasi \\
\hline \hline B1 & 17,22 & a \\
\hline B2 & 21,56 & b \\
\hline B4 & 26,44 & c \\
\hline B3 & 26,56 & c \\
\hline \hline BNT 5 \% & $\mathbf{2 , 9 2 3}$ & \multicolumn{1}{|c}{} \\
\hline \hline
\end{tabular}


Tabel 6. Rata-rata saat munculnya tunas karena pengaruh perlakuan media

\begin{tabular}{|c|c|c|}
\hline \hline Perlakuan & Rerata & Notasi \\
\hline \hline M2 & 21,33 & a \\
\hline M3 & 22,17 & a \\
\hline M1 & 25,33 & b \\
\hline \hline BNT 5 \% & $\mathbf{2 , 5 3 1}$ & \multicolumn{1}{|c}{} \\
\hline \hline
\end{tabular}

Tabel 5 menunjukkan bahwa pada perlakuan biji memberikan pengaruh sangat nyata dimana perlakuan biji B3 dan B4 tidak berbeda secara signifikan tetapi berbeda B1 dan B2. Perlakuan terbaik pada B1 yaitu 17,22 hari. Pada perlakuan media table 6, M2 dan M3 tidak berbeda nyata tetapi perlakuan M1 berbeda nyata (perlakuan terbaik M2 dengan pertumbuhan tunas rata-rata 21,33 hari).

Untuk Perlakuan Biji, B1 mencapai hasil terbaik dimana tunas muncul lebih cepat. Hal ini terjadi karena pada B1 biji tidak ada faktor penghambat untuk perkecambahan yang kemudian diteruskan pertumbuhan tunas.

Untuk perlakuan media yang terbaik adalah M2 yaitu media pasir + pupuk kandang. Meskipun tidak berbeda nyata dengan M3 yaitu media tanah dan pupuk kandang. Hal ini dipengaruhi oleh sifat fisik maupun sifat biologis media. Adanya penambahan pupuk kandang memberikan pengaruh positif terhadap media untuk menahan air. Dimana air adalah faktor utama untuk metabolisme benih dalam perkecambahan. Dari tahap-tahap perkecambahan peran air sangat penting.

Media yang baik untuk perkecambahan maupun untuk pertumbuhan tanaman benih haruslah mempunyai sifat fisik yang baik, gembur, mempunyai kemampuan menahan air dan bebas dari organisme penyebab penyakit terutama cendawan. Tanah dengan tekstur lempung berpasir dan dilengkapi dengan bahan-bahan organik merupakan medium yang baik bagi benih untuk pertumbuhan(Swasono Heddy,1994).

Kondisi fisik dari tanah sangat penting bagi berlangsungnya kehidupan kecambah menjadi tanaman dewasa. Benih akan terhambat perkecambahannya pada tanah yang padat karena benih berusaha keras untuk dapat menembus ke permukaan tanah. Sehingga perlu adanya penambahan pupuk kandang agar tanah menjadi gembur. 


\section{Diameter Batang}

Rata-rata diameter batang pada setiap perlakuan bisa dilihat pada gambar 4. Dimana rata-rata diameter batang berkisar antara 3,10 cm (B1M1) sampai 3,75 cm (B3M3)dan (B4M3). Dengan ini dapat dilihat bahwa diameter batang terbesar terjadi pada (B3M3) dan (B4M3). Pengamatan terhadap diameter batang dilakukan saat usia 70 hari setelah tanam.

Dari hasil analisis ragam terhadap diameter batang tidak terjadi interaksi yang nyata (lampiran 5) antara perlakuan biji dan media, begitu juga pada perlakuan biji. Sedangkan pada perlakuan media menunjukkan pengaruh yang nyata. Hal ini berarti bahwa perlakuan pada biji tidak memberikan pengaruh yang signifikan terhadap diameter batang.

Tabel 7. Rata-rata diameter batang terhadap perlakuan Biji

\begin{tabular}{|c|c|c|}
\hline \hline Perlakuan & Rerata & Notasi \\
\hline \hline B1 & 3,39 & a \\
\hline B2 & 3,44 & a \\
\hline B3 & 3,50 & a \\
\hline B4 & 3,55 & a \\
\hline \hline BNT 5 \% & $\mathbf{0 , 3 6 2}$ & \\
\hline
\end{tabular}

Tabel 8. Rata-rata diameter batang terhadap perlakuan media

\begin{tabular}{|c|c|c|}
\hline \hline Perlakuan & Rerata & Notasi \\
\hline \hline M1 & 3,24 & $\mathrm{a}$ \\
\hline M2 & 3,52 & $\mathrm{ab}$ \\
\hline M3 & 3,65 & $\mathrm{~b}$ \\
\hline \hline BNT 5 \% & $\mathbf{0 , 3 1 4}$ & \multicolumn{1}{|l}{} \\
\hline \hline
\end{tabular}

Dari kedua tabel tersebut diatas dapat dilihat bahwa pengaruh perlakuan biji terhadap diameter batang tidak menunjukkan adanya perbedaan pada semua perlakuan.Perlakuan terbaik pada B4. Sedangkan pada perlakuan media menunjukkan adanya perbedaan. M3 berbeda denngan M1 namun tidak berbeda nyata terhadap M2. Perlakuan terbaik pada M3.

Pada perlakuan media, M3 menunjukkan diameter terbesar, hal ini dipengaruhi oleh sifat-sifat media itu sendiri. Campuran tanah dan pupuk kandang memberikan mineral dan nutrisi yang cukup bagi pertumbuhan tanaman mahkota dewa. Dilihat dari 
pengaruhnya terhadap tinggi tanaman dan jumlah daun juga memberikan manfaat yang sangat baik. Dengan jumlah daun yang cukup banyak memungkinkan tanaman mengadakan proses fotosintesis yang optimal sehingga hasil-hasil fotosintat dapat disalurkan keseluruh titik-titik tumbuh termasuk pembentukan kambium. Dengan hasil fotosintat yang optimal untuk pembentukan kambium mempengaruhi pembesaran batangsehingga didapat diameter batang besar.

\section{Berat Kering Tanaman .}

Tabel 9 Rata-rata berat kering tanaman karena pengaruh perlakuan biji

\begin{tabular}{|c|c|c|}
\hline \hline Perlakuan & Rerata & Notasi \\
\hline \hline B1 & 3,89 & $\mathrm{a}$ \\
\hline B2 & 4,04 & $\mathrm{a}$ \\
\hline B3 & 4,48 & $\mathrm{a}$ \\
\hline \hline B4 & 4,66 & $\mathrm{a}$ \\
\hline \hline
\end{tabular}

Keterangan : angka yang didampingi huruf yang sama menyatakan tidak berbeda pada $(p=0,05)$

Tabel 10. Rata-rata berat kering karena pengaruh media

\begin{tabular}{|c|c|c|}
\hline \hline Perlakuan & Rerata & Notasi \\
\hline \hline B1 & 3,89 & $\mathrm{a}$ \\
\hline B2 & 4,04 & $\mathrm{a}$ \\
\hline B3 & 4,48 & $\mathrm{a}$ \\
\hline \hline BNT 5 \% & 4,66 & $\mathrm{a}$ \\
\hline \hline
\end{tabular}

Keterangan : angka yang didampingi huruf yang sama menyatakan tidak berbeda pada $(p=0,05)$

Dari hasil analisa mengenai berat kering tanaman menunjukan bahwa pada perlakuan biji tidak menunjukkan perbedaan nyata, tetapi pada media menunjukkan perbedaan nyata pada perlakuan M3 (media tanah + pupuk kandang), hal ini karena pada berat tanaman yang paling banyak dipengaruhi kandungan kaebon dalam tanaman.

Kandungan karbon dalam tanaman dipengaruhi adanya proses fotosintesis, dimanakarbon pada proses fotosintesis dipengaruhi adanya suplay unsur hara yang dapat diserap oleh tanaman. Dengan adanya pupuk kandang dan tanah yang mengandung unsur hara yang diperlukan tanaman, maka tanaman akan lebih optimal dalam melaksanakan proses fotosintesis 


\section{KESIMPULAN DAN SARAN}

Dari hasil penelitian pengaruh perlakuan biji dan media tanam terhadap perkecambahan biji mahkota dewa dapat ditarik kesimpulan :Perlakuan biji mahkota dewa yang berbeda memberikan pengaruh yang nyata terhadap tinggi tanaman, pada jumlah daun dan munculnya tunasberpengaruh sangat nyata, tetapi tidak berpengaruh nyata terhadap besarnya diameter batangPerlakuan media pada tanaman mahkota dewa yang berbeda memberikan pengaruh yang sangat nyata pada tinggi tanaman dan saat munculnya tunas, sedangkan pada jumlah daun dan diameter batang berpengaruh nyata.Perlakuan terbaik dalam penelitian ini adalah B1M3 yaitu biji yang tanpa cangkang dan kulit dan media tanah ditambah pupuk kandang dengan tinggi tanaman 9,55 cm ; jumlah daun 12,76 buah ; waktu muncul bunga 12 hari setelah tanam ( 2 minggu); diametr batang 3,54 cm. ; berat kering tanaman 5,7 gram.

\section{DAFTAR PUSTAKA}

Agoes,D , 1994. Aneka Jenis Media Tanam dan Penggunaannya. Panebar Swadaya. Jakarta.

Dwijosepoetro, 1989. Pengantar Fisiologi Tumbuhan. Gajah Mada University Press. Yogyakarta.

Hakim, N, dkk, 1986. Dasar-dasar Ilmu Tanah. Universitas Lampung.

Harjadi, SS. 1993. Pengantar Agronomi. Departemen Agronomi Fakultas Pertanian. IPB.

Heddy, S, 1994. Pengantar Produksi Tanaman dan Pasca Panen. Rajawali Pers, Jakarta

Jumin, HB. 1991. Dasar-dasar Agronomi. Rajawali Press. Jakarta.

Kartasaputra,1980. Teknologi Benih. Bina Aksara. Jakarta.

Lita,S. 2002. Teknologi Benih. Rajawali Pers. Jakarta

Nasution, M.A. 1998. Pengaruh Pemberian Pupuk Kandang dan kalium Terhadap Produksi dan Kualitas Jagung Manis ( Zea mays saccharata) Pada Lahan Kering. Skripsi S-1 Jurusan Budidaya Pertanian. Fakultas Pertanian. Unibraw. Malang. 
Sarief, E.S. 1986. Kesuburan Dan Pemupukan Tanah Pertanian. CV. Pustaka Buana. Bandung

Sitompul, SM dan Bambang G. 1995. Analisa Pertumbuhan Tanaman. Gadjah Mada University Press. Yogyakarta.

Winarto. W.P, Tim Kayasari. 2004. Mahkota Dewa : Budidaya \& Pemanfaatan Untuk Obat. Penebar Swadaya. Jakarta 